\title{
"NOVELA DE NO-FICCIÓN": POLÉMICA EN TORNO A UN CONCEPTO CONTRADICTORIO
}

\author{
Romina Laura García*
}

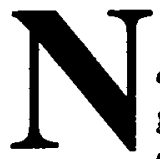

o-ficción es un concepto amplio que se usa para designar a aquellos géneros discursivos que hacen referencia, de un modo u otro, a hechos de lo real, como el ensayo, las crónicas de viaje, las memorias, la biografía y la autobiografía, así como también el relato historiográfico y los diferentes géneros periodísticos.

A comienzos de los años sesenta (podríamos poner como fecha inicial, siguiendo a Tom Wolfe, el otoño de $1962^{1}$ ) algunos periodistas estadounidenses - Gay Talese, Jimmy Breslin o el mencionado Tom Wolfe, entre otros- que trabajaban para periódicos como el New York Herald Tribune y Esquire, comienzan a experimentar sobre un modo muy particular de narrar las noticias. Por un lado, proponen una forma diferente de recoger la información, "metiéndose" en el lugar de los hechos, vivenciándolos, conviviendo con sus protagonistas. Por otro, rompen con los cánones de escritura del periodismo tradicional y descubren

* Universidad Nacional de Mar del Plata

1 Propusimos esa fecha porque Tom Wolfe la señala como el día en que apareció un artículo de Gay Talese, publicado en Esquire y titulado "Joe Louis: el Rey hecho Hombre de Edad Madura", que Wolfe destaca como el primero escrito en el estilo de lo que después llamaría "nuevo periodismo". 
GARCÍA, R. L. "Novela de no-ficción"...

las posibilidades que les ofrecen algunos procedimientos provenientes de la literatura ${ }^{2}$, sin por ello dejar de ser "muy fieles a la realidad" (p. 26), en palabras del mismo Wolfe. Así, el juego con el punto de vista, el cambio de foco, el collage y el montaje, como también la mezcla de diferentes géneros, la transgresión de los signos convencionales de puntuación, las onomatopeyas e interjecciones, el uso del diálogo y del monólogo interior reemplazaron a la estructura piramidal de la noticia, a la construcción en base a las cinco preguntas típicas: ¿Qué?, ¿Quién?, ¿Dónde?, ¿Cuándo?, ¿Por qué?, al narrador en tercera persona fuera del cuadro, al lenguaje general, a la brevedad y la concisión.

Esta nueva forma de escritura de no-ficción viene a desestabilizar todo el aparato genérico tradicional, así como las concepciones aceptadas de "verdad" y "ficción", "literatura" y "periodismo". Estos textos quedan fuera de las clasificaciones establecidas. No son considerados periodísticos en sentido estricto, porque rompen con la idea de objetividad y con las reglas más básicas de la escritura periodística canónica, al tiempo que su inclusión en el campo de la litcratura está siempre sujeta a discusión. Sus productores señalaron que se trataba de un nuevo género que se denominó, entre 1965 y 1966, "nuevo periodismo".

Rechazados tanto por los periodistas de "la vieja guardia" como por los literatos, estos textos constituyen, para Wolfe, un estilo literario nuevo, salido de las filas del periodismo, que supera en calidad de información a los artículos periodísticos tradicionales al tiempo que destrona a la novela como género preferido del público burgués, o mejor, viene a ocupar el lugar que la "novela de literatos", como la llama, ha dejado libre hace rato al abandonar las técnicas del realismo, y convertirse en un objeto intelectual.

En febrero de 1966 aparece la primera edición de un libro que tuvo gran acogida por parte del público y fue clave en el desarrollo del género. Se trata de A sangre fría de Truman Capote, que consistió originalmente en una serie de relatos periodísticos publicados en The New Yorker durante el otoño de 1965, donde se cuenta la historia de dos vagabundos que exterminaron a una familia de granjeros en Kansas.

Capote, que no era periodista sino un hombre salido de las filas de la literatura, un novelista reconocido, declara que $A$ sangre fría no es un texto

2 Aunque Tom Wolfe afirma que se toman las técnicas propias de la novela realista, es evidente que los procedimientos utilizados vienen fundamentalmente de la narrativa de carácter vanguardista que se desarrolla en los sesenta, como el noveau roman o la nueva novela latinoamericana. Esta discusión acerca del carácter realista del género en cuestión será desarrollado en otro artículo. 
periodístico sino un nuevo género literario que acaba de inventar: la novela de no-ficción (nonfiction novel). Frente a los artículos publicados por los nuevos periodistas en periódicos o revistas ${ }^{3}$, la novedad que dice introducir Capote es "novelar", dar forma de novela -y editarlo de modo autónomo, como libro- a un hecho policial que ha conmocionado a la opinión pública ${ }^{4}$.

Esta declaración desató la polémica. Tom Wolfe sale al cruce afirmando que el trabajo de Capote no difiere en nada del de los nuevos periodistas. En primer lugar destaca que el procedimiento de recolección de la información llevado a cabo por el escritor (que, según cuenta, estuvo cinco años investigando y entrevistándose con los asesinos en prisión) es de la misma índole que el realizado por periodistas. Además, señala que ya en 1966 muchos nuevos periodistas habían empezado a publicar libros que, de manera similar a lo hecho por Capote, eran resultado de años de investigación y utilizaban recursos "literarios". Entre ellos cita a $M$, de John Sack, Paper Lion, de George Plimpton o Los Ángeles del infierno: la extraña y terrible saga de la banda de los motociclistas proscritos, de Hunter Thompson, libros con un éxito popular tan rotundo como el de Capote. Los demás literatos se animan a incursionar en este género -según destaca Wolfe- recién en 1968, año en que se publica Los ejércitos de la noche, del reconocido novelista Norman Mailer. Al igual que Capote, cuenta Wolfe, "Mailer estaba aterrado por la etiqueta que le habían puesto -'periodista' - y había subtitulado su libro La novela como historia; historia como la novela". (p. 45)

Detrás de esta polémica subyace la cuestión de cómo legitimar un género que queda fuera de las clasificaciones tradicionales. Capote, como novelista, pretende darle jerarquía literaria diferenciándolo del periodismo. Su actitud, en palabras de Wolfe, era similar a la que había tenido Henry Fielding en 1742. Vale la cita:

3 Por esa época, en 1965, aparece la primera antología de artículos de los nuevos periodistas: Kandy-Kolored Tangerine-Flake Streamline Baby de Tom Wolfe.

4 Sin embargo, el procedimiento de "novelar" un hecho real no es una invención de Capote, como él mismo señala, sino que ya había sido trabajado por importantes escritores. Basta citar someramente algunos títulos anteriores como Diario del año de la peste de Daniel Defoe, Vida en Missisipi de Mark Twain o El inmenso cuarto de Cummings. En el campo de la literatura argentina, el ejemplo más cercano anterior al hito de la publicación de A sangre fría, es la trilogía de Rodolfo Walsh iniciada en 1957 con Operación masacre y completada por ¿Quién mató a Rosendo? (1969) y El caso Satanowsky (1973). Lo que hay que destacar es que estos tex tos no se convierten en objeto de estudio hasta el planteo de Capote, que abre una polémica teórica y crítica en la que pretende incluirse el presente trabajo. 
GARCÍA, R. L. "Novela de no-fícción"...

Cuando Henry Fielding publicó su primera novela, Joseph Andrews, en 1742, estuvo alegando que su libro no era una novela: era un nuevo género literario que había inventado, 'el poema épico cómico en prosa'. (...) Lo que estaba haciendo, naturalmente -y que haría Capote 223 años más tarde-era intentar darle a su obra el sello del género literario imperante en su época, para que los profesionales de la literatura la tomasen en serio. (...) La condición de la novela [en la época de Fielding] era tan baja... bueno, era tan baja como la condición del periodismo de revista en 1965 cuando Capote empezó a publicar $A$ sangre fría en The New Yorker. (p. 57)

Wolfe, como periodista, en un movimiento inverso, busca la legitimación de su actividad a partir de adjudicar al periodismo la creación de este género que, a su criterio, es indiscutiblemente artístico.

A mi modo de ver, si un estilo literario nuevo podía nacer del periodismo, resultaba entonces razonable que el periodismo pudiese aspirar a algo más que una simple emulación de esos envejecidos gigantes, los novelistas. (p. 36-37)

Según Wolfe, el nuevo estilo literario había sido creado por periodistas y los literatos se plegaron a él porque reconocicron sus ventajas. Predice un "tremendo futuro" para lo que propone llamar "novela periodística" o "novela documento", y reclama que "El nuevo periodismo no puede ser ignorado por más tiempo en un sentido artístico". (p. 56)

En 1981 John Hellman se suma a la polémica iniciada por Wolfe y Capote, y enfrenta su punto de vista con el expuesto por Mas'Ud Zavarzadeh en 1976. Señala que, pese a que hubo precedentes en la historia del nuevo periodismo y de la prosa de ficción, los términos "nuevo periodismo" y "novela de no ficción" aparecen en 1965 con la publicación de dos libros clave: uno de ellos es Kandy-Kolored Tangerine-Flake Streamline Baby de Tom Wolfe; el otro, el ya mencionado A sangre fría de Truman Capote. La postura de Hellman en esta controversia es la de considerar que los dos conceptos indican los diferentes orígenes de cada una de estas maneras de escribir pero hacen referencia al mismo tipo de textos. Hellman opina que tanto los novelistas como los periodistas llegaron por distintos caminos a encontrar una manera más eficaz de 
dar cuenta del nuevo juego de la realidad americana. No obstante, se inclina por la denominación común de "nuevo periodismo".

Zavarzadeh, en cambio, marca una distinción entre los dos términos en cuestión. La novela de no ficción, a su juicio, es birreferencial puesto que se pueden distinguir en ella dos campos de referencia: el mundo interno de la narración, que posee el control estético de las artes verbales en general, y el mundo externo, que constituye el contexto experiencial, la "autoridad de lo real". Introduce, en este sentido, el concepto de "ángulo de referencia". Éste determina el grado de elección de la narración en relación con sus dos ejes referenciales y manifiesta hasta qué punto se preserva el equilibrio con el cual la narración se deslizaria hacia lo fictual o lo factual. La birreferencialidad es la tensión entre esos dos polos de referencia.

El empleo de técnicas narrativas que hace el nuevo periodismo, en cambio, copia una textura ficcional pero le da una tensión factual. Según este crítico, los textos del nuevo periodismo, de la misma manera que la historia, la biografía o la novela fáctica, son narraciones factuales, monorreferenciales, y esto es lo que los diferencia de la novela de no-ficción.

Hellman contesta que la distinción entre mono y birreferencialidad es una falacia. Todo lo escrito, señala, es "birreferencial" puesto que cada elemento de un texto se refiere a la vez al mundo externo y a otros elementos lingüísticos y estructurales del propio texto 5 . Por otra parte, afirma que es necesario eliminar la desafortunada e ilusoria distinción entre escritos ficcionales y factuales, porque separa erróneamente la forma estética y el propósito. Para su propuesta se apoya en un criterio de clasificación desarrollado por Frye, quien señala que las estructuras verbales pueden distinguirse de acuerdo a si su sentido final, de conjunto, apunta al exterior o al interior del texto. Frye reconoce dos tipos de textos: los asertivos o descriptivos y los literarios. Mientras en estos últimos el sentido final es interno (inward), en los primeros la estructura verbal está en función de representar elementos externos a ella (su dirección última eś entonces, externa, outward), y es evaluada en términos de adecuación a los mismos. La correspondencia o no entre los signos verbales y el fenómeno referido hace a estos textos verdaderos of falsos respectivamente.

5 Para reforzar esta afirmación, Hellman se apoya en la propuesta de Frye (1957) de que en el acto de lectura, la atención se mueve en dos direcciones a la vez: una es externa o centrifuga. en la que se busca fuera de la lectura, desde la capacidad de asociación entre las palabras y las cosas. La otra es interna o centrípeta, y en ella se trata de desarrollar un sentido a partir de determinados patrones verbales. 
Hellman plantea que un texto asertivo puede subsumir técnicas o efectos propios de uno literario, lo que da como resultado un texto asertivo con textura literaria. De la misma manera, un texto literario puede trabajar con elementos asertivos. Lo importante es lo que él llama el efecto o sentido final, de conjunto, y en relación con esto, hace hincapié en la noción de contrato o acuerdo entre autor y lector. ${ }^{6}$

El nuevo periodismo es claramente, para este crítico, un género literario, porque si bien -por lo establecido en lo que él llama "contrato periodístico" (journalistic contract) entre el autor y el lector- apunta al exterior (outward), tiene una forma y una intencionalidad estética que producen un efecto final interno (inward). Basándose en otra definición de Frye, de que "ficción es arte en prosa", y destacando los elementos "artísticos" o "literarios" del nuevo periodismo, asegura que no hay dificultades lógicas para señalar que se trata de un género de ficción. En este punto Hellman parece caer en una contradicción, porque está homologando el "efecto final interno" propio de los textos literarios, según Frye, con el concepto de ficción que él mismo pretende desterrar como criterio de clasificación.

Por otro lado, señala que el mundo al que hacen referencia estos textos es periodístico: se adhieren a las fuentes primarias de información y a las observaciones del autor -0 su compilación de observaciones de otros- sobre eventos contemporáneos. Esto los distingue de la novela histórica, que se basa en hechos más lejanos, trabaja con fuentes secundarias e incluye considerable

6 Hellman (1981) utiliza de manera indistinta las palabras "contrato" (contract) o "acuerdo" (agreement) para dar cuenta de lo que diferencia a los textos del nuevo periodismo de los de ficción propiamente dicha contemporáneos. Señala que, en ambos, el autor contrae un acuerdo con el lector respecto de la relación entre sus referentes y el mundo exterior. Mientras en la ficción propiamente dicha el autor sólo tiene que dar cuenta de la cohesión interna del mundo imaginado, en el nuevo periodismo debe convencer de la veracidad de sus fuentes y de su integridad personal. Este contrato o acuerdo entre autor y lector tiene un efecto crucial sobre la manera en que el texto es recepcionado. Si bien reconoce que, como todo contrato, no tiene efecto ni legitimidad a menos que sea aceptado y tenga la adhesión de ambas partes, recarga la responsabilidad en el autor. Declara que un autor puede realizar un contrato periodístico convincente de muchas maneras. La primera, por el método simple y efectivo de señalar que el texto en cuestión pertenece al género de no ficción. Pero puede reforzar esta postura mediante la explicación -que generalmente se da en el espacio de los marcos textuales o paratextos- de que el libro está completamente basado en una detallada descripción de observaciones propias o hechas por otros. Otra forma es elaborar una detallada descripción de los materiales disponibles para él, o exponer varios documentos y datos verificables dentro del texto. Mediante otros recursos, como el desarrollo de revelaciones personales, le será posible convencer al receptor de su honestidad y credibilidad. Si un autor, de algún modo, causa en el lector serias dudas acerca de la validez del contrato periodístico, el efecto estético se verá alterado o debilitado, y esto puede afectar a la evaluación crítica. 
invención. Sin embargo afirma que en el nuevo periodismo los elementos periodísticos han sido seleccionados, combinados y transformados estilísticamente para crear una experiencia estética que encarne la expresión personal del autor y su interpretación de los acontecimientos. Son construcciones que no representan hechos sino una vivencia individual de los mismos. Los lectores, a su juicio, se acercan a este tipo de trabajos por su encanto particular y no específicamente para informarse.

Otro punto discordante entre Hellman y Zavarzadeh es la cuestión de la terminología con que se hace referencia a los constituyentes narrativos de este tipo de textos. Zavarzadeh se opone a aquellos que aplican, en el análisis del género, términos como personajes y argumento o trama, que son los mismos que se utilizan en la novela de ficción. Afirma que la novela de no-ficción tiene premisas epistemológicas totalmente distintas, por lo cual desarrolla un conjunto de conceptos críticos, a su juicio, más adecuados.

Distingue en el género dos componentes básicos: el "imaginario" y el "experiencial". En el primero se encuentran el "macrolenguaje" y la "arquitectura" de la novela. En el segundo, se habla de "personas" y "actemas".

En la novela de no-ficción no hay argumento o trama, entendida como una matriz de movimiento que controla la intensidad dramática, objetiviza y pinta el orden de realidad entrevisto por el autor. En su lugar, Zavarzadeh ofrece el concepto de "actema", que es el resultado de la configuración de los hechos experienciados. Del mismo modo, tampoco se puede hablar de una organización dramática en estos textos, sino de una "organización mimética", en que la matriz de las situaciones es la inevitabilidad. El suspenso es también de corte diferente respecto de la novela de ficción: mientras en ella el suspenso es situacional, en la no-ficción es de carácter "epistemológico" o "suspenso inscripcional", puesto que los hechos a los que se hace referencia son del dominio público y el lector sabe lo que va a suceder; su interés se genera por el modo en que son transcriptos esos acontecimientos.

Tampoco es posible para Zavarzadeh hablar de personaje en este tipo de novelas, dado que en ellas no se trata de figuras compuestas por la invención del autor, sino de individuos reales. Propone, entonces, llamarlos "gente". Hay dos funciones básicas de la "gente" en la novela de no-ficción, que el crítico distingue con los conceptos de "actante" y "actuado".

Hellman se opone a esta propuesta en coherencia con su concepción de los trabajos del nuevo periodismo como textos ficcionales. Señala que en las aproximaciones críticas pueden utilizarse perfectamente los conceptos que se aplican a la ficción tradicional, puesto que los textos del nuevo periodismo 
GARCÍA, R. L. “Novela de no-ficción"...

revelan la presencia tanto de los recursos más básicos como los más sofisticados de la ficción desde el siglo XVIII hasta la actualidad.

Defiende la noción de personaje por sobre la de gente, apelando al hecho de que los personajes están hechos de palabras. Dada la naturaleza del lenguaje, no es posible poner una persona viviente en una página. Sólo se consigue una construcción verbal -un personaje-producto de las impresiones del autor sobre la persona viviente, la selección y ordenamiento de dichas impresiones, y finalmente, la mediación que sobre ellas hace el lenguaje.

Del mismo modo, se opone a la afirmación de Zavarzadeh de que la novela de no-ficción no tiene argumento en el sentido tradicional, porque el autor no puede modificar los hechos en función de expresar su propia visión a través de ellos. Hellman sostiene que si bien el contrato periodístico que se establece en este tipo de textos no permite que se alteren los elementos reales y hasta probablemente impida la omisión de algunos detalles, el autor tiene libertad para seleccionar y ordenar una secuencia de eventos.

Tampoco considera que - como apunta Zavarzadeh- la novela de noficción no tenga suspenso, entendido como la convencional anticipación y expectación del lector sobre el desarrollo de situaciones en la narrativa. Para Hellman, el suspenso -tanto en estos textos como en los de ficción tradicionalno depende de la ignorancia acerca del inminente desarrollo de los eventos sino de la experta construcción de la secuencia.

Esta discusión, concluye, sirve para demostrar que el nuevo periodismo es, efectivamente, un género de ficción aunque haga referencia a hechos externos, porque, como las novelas tradicionales, el efecto final apunta hacia su propia forma.

Como puede observarse, la base sobre la que se estructura este debate es la búsqueda de la forma de demostrar que estos textos son efectivamente literarios. En el fondo, parece que la única manera de legitimarlos, de darles entidad como género, es a través de su ingreso en el ámbito "sagrado" que parece ser la literatura. Zavarzadeh y Hellman, desde una mirada crítica, renuevan la polémica inaugurada por Capote y Wolfe diez años antes.

Zavarzadeh, inclinándose en favor de la posición de Truman Capote, propone considerar a la novela de no-ficción (y dejar fuera de la discusión -repitiendo el gesto de su antecesor- a los trabajos del nuevo periodismo, que para él son narraciones meramente "factuales") como una literatura propia de los momentos de crisis y de situaciones límite, que está en relación con el posmodernismo cultural de la posguerra de la Segunda Guerra Mundial, dado su cuestionamiento de la idea de arte como totalidad y la postulación de lo que sería un no-arte. Vincula a ésta con la producción de escritores posmodernos 
como Beckett y la narrativa no totalizante. Destaca como antecedentes "prehistóricos" a Diario del año de la Peste de Daniel Defoe, Vida en Missisipi, de Mark Twain, $\mathrm{y}$ algunas producciones isabelinas.

La "narrativa de situaciones extremas" -como llama Zavarzadeh a las novelas de no-ficción- es el género dominante del presente período cultural, de la misma manera que el drama lo fue en el período isabelino, los discursos políticos en la época de Augusto, o el poema narrativo en el período romántico.

Hellman se posiciona en la vereda de enfrente y elabora una propuesta que da sustento teórico y profundidad crítica a los reclamos wolfianos. El nuevo periodismo (nótese que esta terminología es la que propone Wolfe y engloba tanto a los artículos breves escritos por periodistas como a la nonfiction novel "inventada" por Capote) es literatura por los procedimientos "artísticos" con los que trabaja. Estos procedimientos son los que otorgan al nuevo periodismo un efecto final interno, un sentido que vuelve sobre su propia forma, de la misma manera que ocurre, según Frye, con la literatura. Además, agrega a su argumentación una breve referencia al uso -aunque no profundiza este aspectoseñalando que los lectores se acercan a ella porque constituye una experiencia estética atractiva y no por una necesidad de información. Lo que Hellman no tiene en cuenta es que, como ocurre con los textos denominados "asertivos" por Frye, los del nuevo periodismo son juzgados y validados como género según un criterio de "veracidad", es decir, por la correspondencia entre su referencia y lo real, y este aspecto es el que los separa de la literatura.

$\mathrm{Si}$ bien reconoce que todo escrito es por sí mismo ficcional, que no es posible dar cuenta de lo real porque hay siempre mediaciones y la más importante de ellas es el lenguaje, algunas veces incurre en una contradicción al utilizar el término "ficcional" como sinónimo de "literario".

Un planteo similar, pero aplicado al discurso historiográfico, es el propuesto por Hayden White (1985). Él parte de la concepción del lenguaje como mediador y señala que el historiador no trabaja con hechos sino con discursos. Hay una imposibilidad esencial de la escritura de llegar a lo "real".

Los hechos están formados en el relato por la supresión o por la subordinación de algunos de ellos y la luz de otros, por caracterización, repetición de motivos, variación del tono y punto de vista, estrategias descriptivas alternativas y similares, en suma todas las técnicas que esperariamos normalmente encontrar en el encadenamiento de una novela o de una obra de teatro. (p. XXIV) 
GARCÍA, R. L. "Novela de no-ficción"...

Las narraciones históricas son vistas, entonces, como "ficciones verbales" (White, 1985, p. XXI) aunque esto "de ninguna manera desmerece el status de narraciones históricas como suministradoras de un tipo de conocimiento" (White, 1985, p. XXVI).

Hayden White parece considerar a la literatura como sinónimo de "ficción". Esto le permite señalar como literario hasta al discurso histórico más riguroso, por tratarse de una ficción, una construcción lingüística. De un razonamiento parecido parte Hellman para incluir al género mal llamado-según acabamos de ver-novela no-ficción (que él denomina nuevo periodismo) dentro de lo que es conocido como literatura.

Sin embargo parece demasiado aventurado decir que el relato histórico de corte positivista sea literario simplemente porque no tiene procedimientos difcrentes de los textos literarios. En todo caso, cabe acordar que todo texto es una construcción. Eso no quiere decir que todo sea literatura, sino que pone al descubierto que, en definitiva, los procedimientos por sí solos no hacen literario a un texto.

Hayden White sostiene que lo que separa a los textos con referentes reales de aquellos que tienen referencia imaginaria es simplemente "la presunción de una diferencia ontológica entre sus respectivos referentes" (White, 1987, p. 12). Según la propuesta más acertada de Hellman, esta distinción depende fundamentalmente del contrato o del acuerdo contractual ("contractual agreement") entre autor y lector.

A esta polémica acerca de la pertenencia del género al campo de la literatura se suma la crítica argentina Ana María Amar Sánchez. En su trabajo acerca de Rodolfo Walsh también pretende mostrar que estos textos son literarios. Para ello comienza planteando, respecto de la discusión acerca del término "novela de no-ficción", que si la novela ha tenido siempre como norma la violación de los límites, y desde los comienzos se apoyó en géneros extraliterarios, la no-ficción podría considerarse como novela en sentido amplio. Pero por otro lado, observa que la "no-ficción" es un concepto que abarcaría otros textos (Hidalgo, Luis Pérez, Arlt). Propone, entonces, la noción de "Discurso narrativo no-ficcional" de la que participaría el relato de no-ficción. Esto remite a los orígenes de la novela como género, puesto que novela y noticia tienen origen común.

Sin embargo, la crítica -igual que Hayden White y Hellman-señala que es necesario superar la demarcación entre ficción y realidad en el trabajo con textos. Por eso sugiere hablar en este caso de "relatos testimoniales" o "documentales", denominación que nos parece hasta el momento la más adecuada y que implementaremos en adelante. 
Amar Sánchez conecta al género con el proyecto de "literatura fáctica" desarrollado por Brecht, Benjamin y Eisler: "El género se integra a una tradición que propone un arte vinculado con lo político, pero para ello privilegia la renovación formal como único medio de lograr la desautomatización del lector"(p. 27). Esta relación no nos parece del todo acertada porque los relatos testimoniales están bastante lejos de una propuesta brechtiana. En general no buscan desautomatizar al lector, sino, por el contrario, "envolverlo" en la ilusión referencial a la manera realista para convencerlo de la verdad de lo que se dice, e incluso, en algunos casos, para instarlo a una toma de partido.

$\mathrm{Al}$ referirse a los cánones literarios, la crítica señala que

La literatura (...) se define en términos de lo que algún grupo social, alguna institución llaman y usan como literatura. No hay rasgos caracteristicos de los discursos literarios que no puedan aparecer también en otros tipos de discurso. Son los factores históricos e ideológicos los que determinan la aceptación y los límites de la literatura.(p. 29)

Estamos de acuerdo con esta hipótesis salvo en que consideramos que falta una aclaración: ¿cómo es que se usa la literatura? ¿cuál es el modo de lectura que convierte a los textos en literarios? Amar Sánchez no da cuenta de este aspecto en su trabajo. Por el contrario, esta definición de literatura se contradice con su modo de trabajar. Porque para leer la no-ficción no toma en cuenta factores extraliterarios sino -de la misma manera que Hellman- se centra en los procedimientos de escritura. Dice que éstos por sí solos no definen lo literario pero es el único criterio que utiliza para trabajar los textos de Walsh.

La adopción, por un lado, de formas no canonizadas en los relatos documentales -sigue-implica una toma de posición frente a la literatura como institución. Una declaración política y estética. El uso de formas "elevadas", por otro, hace que se abandone la inmediatez de la nota y se constituyan en relatos, establezcan su propia filiación y se erijan como literatura. Según el razonamiento de Amar Sánchez, entonces, lo que hace que estos textos se integren a lo considerado como literario son los procedimientos. Esto refuerza la contradicción con su definición de literatura. Lo que parece querer decir es que los relatos de este tipo tienen una voluntad deliberada de mostrarse como literatura. Pero no hace referencia al uso.

En definitiva, la cuestión acerca de la pertenencia o no de estos textos a la literatura tiende a caer por su propio peso. Es una pregunta que va destinada 
GARCÍA, R. L. "Novela de no-ficción"...

a no tener respuesta. El relato testimonial es un género con reglas propias que se caracteriza fundamentalmente por la hibridación discursiva, la marginalidad respecto de los cánones de escritura, el no pertenecer a ninguna categoría preestablecida. No es necesario ponerle el mote de "literario" para legitimarlo. Al contrario, su principal interés está en el doble juego que establece entre su carácter periférico respecto de los géneros institucionalizados y su posición central en el gusto del público.

\section{RESUMEN}

En este artículo se pretende dejar esbozado un estado de la cuestión en torno a la problemática teórica y crítica del género conocido como "novela de no-ficción", "nuevo periodismo" o "novela testimonial". Se ponen a dialogar las propuestas desarrolladas por Tom Wolfe, Truman Capote, John Hellman, Mas'Ud Zavarzadeh, Hayden White y Ana María Amar Sánchez, que resultan ser las más significativas en el estudio del tema, en función de dejar planteada la polémica, que gira en torno a tres preguntas clave: ¿qué es, cuál es el origen y qué nombre debe ponérsele a ese tipo particular de escritura referida a hechos reales?, ¿el género en cuestión entra o no en lo considerado como literatura? y finalmente, ¿cómo concebir a esas producciones desde una teoría de la representación?

Palabras-clave: literatura, periodismo, ficción.

\section{RESUMO}

Neste artigo pretende-se deixar esboçado um estado da questão em torno da problemática teórica e crítica do gênero conhecido como "novela de não-ficçāo", "novo jornalismo" ou "romance de testemunho". Põem-se a dialogar as propostas desenvolvidas por Tom Wolfe, Truman Capote, John Hellman, Mas'Ud Zavarzadeh, Hayden White e Ana Maria Amar Sánchez, que resultam ser mais significativas no estudo do tema, em função de deixar colocada a polêmica, que gira em tomo de três perguntas-chave: o que é, qual é a origem e que nome deve dar-se a esse tipo particular de escritura que se refere 
a feitos reais?, o gênero em questāo entra ou não no que é considerado literatura?, e finalmente, como considerar essas produções a partir de uma teoria da representação?

Palavras-chave: literatura, jomalismo, fiç̧ão.

\section{BIBLIOGRAFía}

AMAR SÁNCHEZ, Ana María. El relato de los hechos. Rodolfo Walsh: testimonio y escritura. Rosario: Beatriz Viterbo, 1992.

FRYE, N. Anatomy of Criticism. Princeton: Princeton University Press, 1971.

HELLMAN, John. Fables of fact: the new journalism as new fiction. University of Illinois Press, 1981.

WHITE, Hayden. El texto histórico como artefacto literario. In: Tropics of Discourse: essais in cultural criticism. Baltimore and London: The John Hopkins University Press. Trad. de Elena Tardonato Faliere e Nora E. Bouvet. Argentina: Universidad Nacional de Rosario, 1985.

El contenido de la forma: narrativa, discurso y representación histórica. Barcelona: Paidós, 1992.

WOLFE, Tom. The new journalism. Tom Wolfe; E. W. Johnson (Ed.). New York: Harper and Row. Versión en español: El nuevo periodismo. Barcelona: Anagrama, 1992.

ZAVARZADEH, Mas'Ud. The mythopoetic reality: the postwar american nonfiction novel. The University of Illinois Press, 1976. 